\title{
Leiomioma hepático em paciente imunocompetente
}

\section{Hepatic leyomioma in an immunocompetent patient}

\author{
Antonio Nocchi Kalil, tCBC-RS1; Marcelo Tonding Ferreira²; Fernando Ressler ${ }^{3}$; Cláudio Zettler ${ }^{4}$
}

\section{INTRODUÇÃO}

Comatis om a evolução dos exames de imagem, o diagnóstico das lesões hepáticas assintomáticas do fígado torna-se cada vez mais importante, com diversos tipos de doenças sendo consideradas no diagnóstico diferencial. No entanto, em algumas situações, permanece difícil de determinar o tipo de doença no pré-operatório ${ }^{1,2}$. Os leiomiomas hepáticos são neoplasias extremamente raras, tendo sido relatadas em pacientes jovens com algum tipo de imunossupressão, como SIDA ou pós transplante, ou menos freqüentemente em adultos de meia idade sem doença de base ${ }^{3}$. Relatamos o caso de uma paciente com esta apresentação atípica desta rara neoplasia, discutindo sua apresentação clínica e seu tratamento.

\section{RELATO DO CASO}

Trata-se de uma paciente feminina de 44 anos, previamente hígida, com sensação de desconforto abdominal e massa palpável no hipocôndrio direito. Os exames laboratoriais não evidenciaram alterações e os testes sorológicos para o vírus HIV, hepatite $\mathrm{B}$ e $\mathrm{C}$ foram negativos. Foi submetida à investigação com ecografia abdominal, que demonstrou lesão heterogênea próxima a vesícula biliar de 5,7cm, e com tomografia computadorizada, que demonstrou lesão hepática de aproximadamente $6 \mathrm{~cm}$ na borda inferior do fígado, junto ao leito vesicular (Figura 1). A lesão tinha aspecto heterogêneo, bastante hiperdensa, tardia na fase venosa e com realce periférico. A cintilografia com hemácias marcadas com 99n Tc-pirofosfato foi negativa para a presença de hemangioma. Em virtude destes achados, e por se tratar de nódulo indeterminado pelos exames de imagem e também pela presença de sintomas, a paciente foi submetida à hepatectomia atípica para ressecção da lesão. O pós-operatório transcorreu sem complicações, com a paciente recebendo alta em quatro dias.

O exame anátomo-patológico da peça cirúrgica evidenciou uma lesão nodular de 7,0x 6,0 x 4,5 cm, compatível com diagnóstico de neoplasia de músculo liso (leiomioma) (Figura 2), o que também foi evidenciado na imunoistoquímica (Figura 3), que foi positivo para Actina, Desmina ,bcl-2 e Ki-67.

\section{DISCUSSÃO}

As lesões hepáticas estão cada vez mais sendo diagnosticadas através da realização mais freqüente dos métodos de imagem, mantendo-se ainda difícil de determinar o diagnóstico antes do procedimento cirúrgico em um número pequeno de casos ${ }^{1,4,5}$. A busca do conhecimento de cada tipo histológico e sua apresentação clínica ajuda o cirurgião no manejo deste dilema.

Neste caso observamos tratar-se de uma lesão rara, situação observada com maior freqüência em doentes com SIDA ou imunossupressão pós transplante ${ }^{5}$. Estas situações predispõem o indivíduo, especialmente crianças, ao aparecimento de lesões infreqüentes na prática clínica diária, como tumores de músculo liso no fígado, pulmão, traquéia e trato gastrointestinal. Também tem sido referida a associação com presença do vírus EpsteinBarr, como foi descrito por Prevot et al. ${ }^{5}$.

No entanto, sua apresentação em pacientes sem evidência de imunossupressão, como no caso em questão, tem sido relatado muito raramente na literatura. Do nosso conhecimento, apenas 13 casos foram descritos desde a

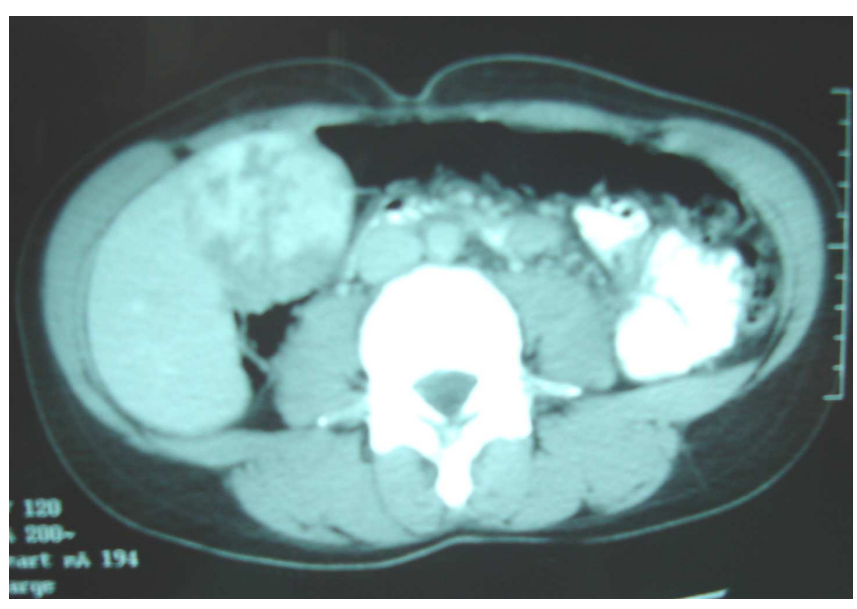

Figura 1 - Tomografia computadorizada mostrando lesão heterogênea próxima ao leito vesicular.

Trabalho realizado no Serviço de Cirurgia Geral da Santa Casa de Porto Alegre e Fundação Faculdade Federal de Ciências Médicas de Porto Alegre (FFFCMPA).

1. Chefe do Serviço de Cirurgia Geral e Oncológica do Complexo Hospitalar Santa Casa de Porto Alegre e Professor do Departamento de Cirurgia da Fundação Faculdade Federal de Ciências Médicas de Porto Alegre (FFFCMPA) - Porto Alegre - RS-BR; 2. Médico Residente do Serviço de Cirurgia Geral da Santa Casa de Porto Alegre- RS- BR; 3. Acadêmico de Medicina da Fundação Faculdade Federal de Ciências Médicas de Porto Alegre. RS-BR; 4. Patologista do Complexo Hospitalar Santa Casa de Porto Alegre e Professor de patologia da FFFCMPA. RS-BR. 


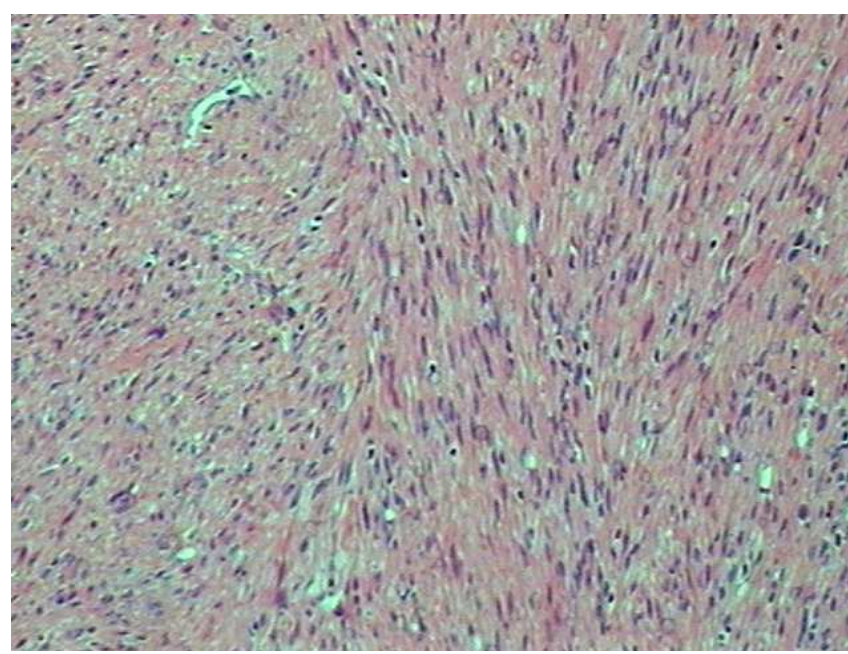

Figura 2 - Neoplasia de músculo liso do tecido hepático.

apresentação da neoplasia por Damel, em 1926'. Estes tumores são geralmente únicos e menores do que $10 \mathrm{~cm}$. O maior deles foi descrito por Herzberg et al., que apresentou $19,5 \mathrm{cms}$ e $1920 \mathrm{gs}^{2}$. Os pacientes tinham geralmente entre 30 e 60 anos de idade, sendo mais comum o relato em mulheres, o que ocorreu também com a paciente do caso em tela, feminina e com 44 anos de idade.

Os pacientes que se apresentam com leiomiomas hepáticos e que não apresentam imunodeficiência evidente descobrem a lesão depois de apresentar desconforto abdominal em hipocôndrio direito ou sendo achados em exames de imagem realizados por outra razão ${ }^{3}$. Os exames de imagem geralmente realizados são ecografia abdominal e a tomografia computadorizada. Os achados na tomografia são variáveis, mas em diversos relatos esta documenta realce da periferia da lesão após contraste ${ }^{2,3}$, como ocorreu no caso relatado. O mecanismo do realce da borda da lesão poderia estar relacionado com os vasos capilares

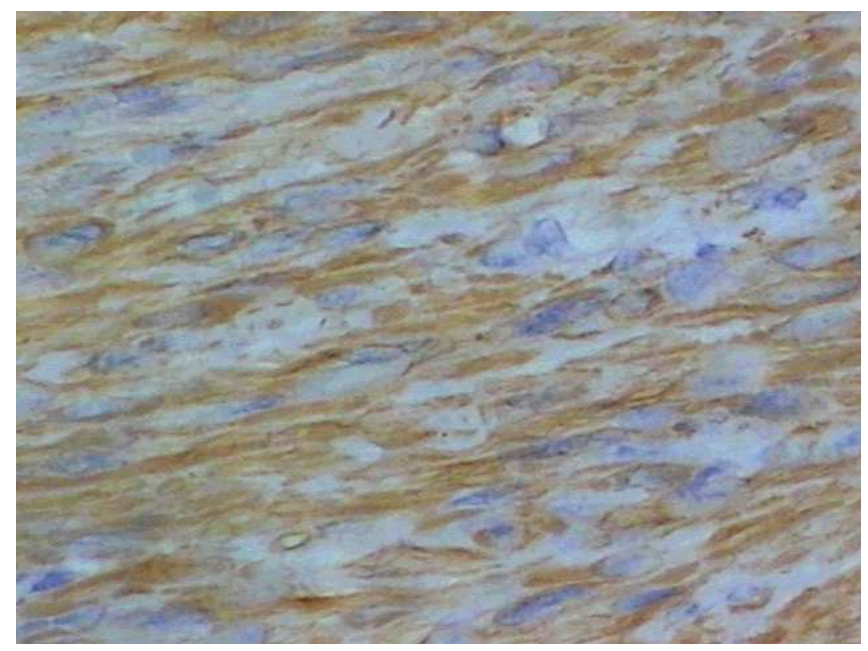

Figura 3 - Perfil imunoistoquímico compatível com leiomioma.

hiperplásicos dilatados encontrados nos exames histopatológicos da lesão². No entanto, nenhuma característica destas neoplasias se mostrou eficaz para diferenciálas de carcinoma hepatocelular, adenoma hepático, carcinoma fibrolamelar, colangiocarcinoma periférico e angiomiolipoma em exames de imagem. Este fato, ou seja, a dificuldade em estabelecer o diagnóstico definitivo no pré-operatório, reforça a necessidade de indicação de hepatectomia nos pacientes com esta suspeita diagnóstica.

Os relatos desta neoplasia na literatura são escassos, mas existe a tendência de que este tipo de lesão seja cada vez mais diagnosticada, tanto pela evolução dos métodos de imagem, quanto pelo aumento do número de pacientes imunossuprimidos, especialmente aqueles com SIDA ou pós-transplante. Devemos lembrar dos leiomiomas no diagnóstico diferencial das lesões hepáticas em pacientes com ou sem imunossupressão, para que uma conduta apropriada seja tomada em cada caso.

\section{A}

Diagnosis and treatment of hepatic tumors are a challenge for the surgeon in some situations. There are many histologic types of these neoplasms, and their diagnoses are increasing. Leyomioma of the liver is a rare pathology that is presented in this article in a 44 years old woman without immunosuppression. A review about its clinical aspects, image diagnosis and surgical therapy is discussed, based on the world medical literature.

Key words: Leiomyoma. Liver. Liver neoplasms. Immunocompetence.

\section{REFERÊNCIAS}

1. Damel R. Ein operierter fall von leber-myom. Virchows Arch. 1926; 261:881-4

2. Herzberg AJ, MacDonald JA, Tucker JA, Humphrey PA, Meyers WC. Primary leyomioma of the liver. Am J Gastroenterol. 1990; $85(12): 1642-5$.

3. Hollands MJ, Jaworski R, Wong KP, Little JM. A leiomyoma of the liver. HPB Surg. 1989; 1(4):337-43.

4. Kanazawa N, Izumi N, Tsuchiya K, Sakurai K, Hamano K, Itakura J et al. A case of primary leiomyoma of the liver in a patient without evidence of imunossupression. Hepatol Res. 2002; 24(1):80

5. Prévot S, NérisJ, de Saint Maur PP. Detection of Epstein Barr virus in a hepatic leiomyomatous neoplasm in an adult human immunodeficiency virus-1 infected patient. Virchows Arch. 1994; 425(3):321-5.
Recebido em 20/04/2006

Aceito para publicação em 18/06/2006

Conflito de interesse: nenhum

Fonte de financiamento: nenhuma

\section{Como citar este artigo:}

Nocchi A, Ferreira MT, Ressler F, Zettler C. Leiomioma hepático em paciente imunocompetente. Rev Col Bras Cir. [periódico na Internet] 2009; 36(4). Disponível em URL: http://www.scielo.br/rcbc

\section{Endereço para correspondência:}

Antonio Nocchi Kalil

E-mail: ankalil@terra.com.br 